\title{
SUPPLY CHAIN MANAGEMENT SOFTWARE SYSTEMS INTEGRATION AND VERSION UPGRADES: VENDOR AND CUSTOMER BASED FRAMEWORK
}

\author{
Ganesh Vaidyanathan, Indiana University South Bend, gvaidyan@iusb.edu \\ Asghar Sabbaghi, Indiana University South Bend, Sabbaghi@iusb.edu \\ Yan Fu, Indiana University South Bend, yanfu79@yahoo.com
}

\begin{abstract}
Integration and upgrade phases of an information systems project are as critical to an organization as the first time the system is implemented. In order to make the ex-post implementation of an IT project completely successful and sustain the adopted information systems, the basic definition of success needs to be extended to include customer satisfaction factors as well as vendor capabilities. This study focuses on identifying the key elements that managers consider when making the decision to upgrade and integrate supply chain management systems that are already in use. We present a framework on both vendor and customer perspectives in the evaluation of supply chain management software systems integration and version upgrades.
\end{abstract}

\section{INTRODUCTION}

Supply chain management (SCM) has received much attention in an intensified global market due to its key role in the integration of key business processes within and outside organizations. It has been widely recognized that actions taken by one member of the chain can influence the profitability and survival of all others in the chain [15]. As the members of supply chain successfully streamline their own operations, the next opportunity for improvement and a prime source of competitive advantage is through better coordination with their suppliers and customers [23]. Therefore, a well coordinated and an integrated supply chain management solution is needed to help manage efficient and effective flow of materials, information, and funds across the entire supply chain, from suppliers to component producers to final assemblers to distributors, and ultimately to the consumer.

Important applications must run continuously and without interruption, and yet also must be changed to fix bugs or upgrade functionality [12]. New Internet technologies such as e-procurement software and advanced supply chain planning systems can greatly simplify integration and implementation [11]. At the same time, the software needs to have a seamless upgrade path so that the release of new or changed features does not compromise existing integration or functionality [10]. The SCM software market has a lot of players, and many of them are tied to specific industries as deep knowledge of an industry and its partner networks is a key factor in the creation and support of SCM software [19]. Some of the top SCM solution providers are SAP, Oracle, Infor, i2 Technologies, and Manhattan Associates. For most of these venders, SCM software contains a series of individual software applications. Since none of them has a complete single package for each component of supply chain management, SCM integration and periodical upgrading becomes necessary and important for businesses to achieve supply chain excellence. When it comes to deciding whether integration or upgrading is needed, what key elements do managers consider when making those decisions? Moreover, when choosing a SCM solution for SCM integration or upgrading, how do managers decide which solution fits their business the best?

Customers will judge the quality of software maintenance differently from that of software development [22] which means that to deliver high quality results in software maintenance, both the functional quality and the technical quality dimensions are important. In order to provide highquality software maintenance for the customers, different and additional processes are needed from those provided by high-quality software development vendors [22]. In this case, are there different factors that are considered by vendors and customers in choosing software solution for SCM integration or upgrading? If so, what are those factors? There is a gap in literature in answering these questions as evidenced by researchers who claim that far less attention has been devoted to the post implementation activities of maintenance and upgrades [3].

The objective of this paper is to identify the key elements that customer managers consider when making the decision to upgrade and integrate supply chain management system that are already in use. We use SCM as a test bed to identify such elements as SCM software tends be unique with respect to integration and version upgrades. We develop a framework to understand the key elements used by managers when they decide on integration and upgrading of supply chain management systems. 
The structure of this study is as follows. In the next section, we discuss the details of SCM system integration and upgrades. In the following section, we illustrate the differences between vendor and customer perspectives on integration and upgrades and the development of the framework. The last section includes the conclusion, limitations, and future work.

\section{SCM SYSTEM INTEGRATION AND UPGRADES}

Many vendors have positioned themselves to integrate SCM components to their software packages so that they may offer fully integrated enterprise application architecture to business community [31]. SCM software is often viewed as a series of individual software applications by vendors. Most of the major supply chain functions such as (1) planning, (2) sourcing, (3) manufacturing, (4) delivering, and (5) returning have their own specific software integrated into the vendor package. Some large vendors have attempted to assemble many of these different software applications together under a single roof, or at least connect them together with some interfaces, but no one has yet a complete package of their own. Integrating the different pieces of the applications together could be an on going process. Currently, perhaps the best way to think about supply chain software is to separate it into software that helps to plan the supply chain, Supply Chain Planning Software, and software that helps to execute the supply chain steps themselves, Supply Chain Execution Software.

Supply chain planning software uses mathematical algorithms to help improve the flow and efficiency of the supply chain and reduce inventory. This type of software is entirely dependent upon information for its accuracy. Planning applications are available for all five of the major supply chain steps, while we believe the most valuable one is demand planning, which determines how much product will satisfy different customers' demands. Supply chain execution software is intended to automate the different steps of the supply chain. This could be as simple as electronically routing orders from manufacturing plants to suppliers for the manufacturing processes needed to make products.

SCM components are available in Enterprise Resource Planning (ERP) systems [14] and since the answers from SCM lead to significantly superior results for the company's business drivers, leading ERP vendors such as SAP and Oracle have developed new advanced planning modules and other components of SCM [6]. In these types of SCM environments, maintenance activities originate from two main sources that include customers and vendors [21]. The customer includes requests for enhancement, bug fixes, ongoing system support, and helpdesk. The vendor support package or patch and upgrade, which are distributed by the vendor but implemented by the customer on its system [21]. A support package or patch contains corrections and further adjustments due to legal changes, and minor corrections for errors in the repository or data dictionary enhancements for an installed version. The customer could upgrade the installed version with a version readily available on the market. Upgrading an installed version to a new version is part of ex post implementation activities [21].

Given the complexity of maintenance, enhancement, and upgrade of SCM solutions, their integration and upgrades become challenging for managers. In order for business to streamline operations as well as better coordinate with their supplier and customers, it is necessary for them to integrate their supply chain solution or upgrade periodically to improve business efficiency and productivity. In addition, as SCM providers try to streamline their solutions to connect different software pieces together under a single solution suite, the managers face the question of whether to keep up with the SCM vendors with upgrading and obtain additional services. What are they currently considering in this complex decision making process and what should they be consider?

\section{SCM INTEGRATION AND UPGRADES}

In this section, we explore the various factors that vendors and customers face from their perspectives in the integration and upgrades of the software.

\section{Vendor Perspective}

Many SCM vendors are busy checking off the industry-specific requirements with new releases in order to stay competitive. SAP's SCM software is designed first to meet the needs of a horizontal universe; then specialized vertical units within the company add specific process enhancements [29]. The need for improved visibility across the entire supply chain is also driving the new releases among software vendors [1].

In addition to the market requirements, most SCM software vendor companies would consider the criteria such as fixing customer identified issues. Moreover, for successful software process improvement a software process must be constantly monitored and evaluated in order to determine its stability [2]. Lucas [18] recommends that performance improvement is of utmost importance to customers in their decision to obtain systems from vendors. Evolutionary software maintenance 
has blossomed because of the ease of adding new functionalities into a system through software improvements but at the same has placed an additional risk [9].

A number of architectures have appeared recently to facilitate the integration of externally created components and when a software component is integrated into a system, it must support the style of the interactions of the system's architecture in order to work together with other components [30]. In response to traditional and emerging markets, software vendors are realizing they must satisfy the needs of a wide range of companies and to develop possible to ensure system still works the way customers expected. This methodology not only ensures customer satisfaction but also helps improving the software quality. Then, depends on the objectives of the company and the direction of the product in the market, the remaining criteria is prioritized and considered. If improving customer satisfaction for current solution user is the major company goal for the release period, improving stability and performance of the solution are considered with more weight.

The efforts needed for each criterion during the new release will depend on their acceptability in

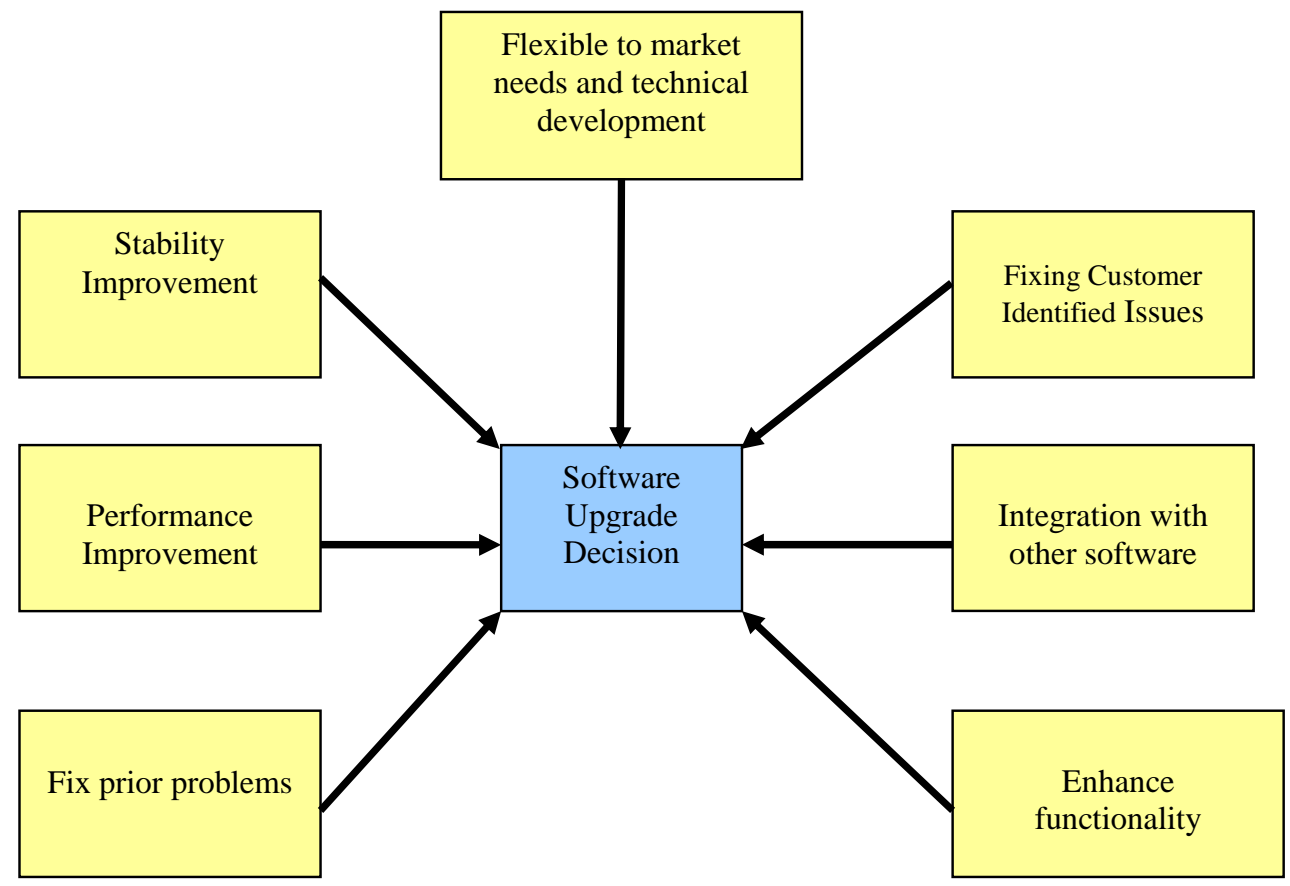

Figure 1: New Software Release Decision Factors - Vendor Perspective

applications tailored to each niche [7]. Furthermore, flexible software vendors that successfully adapt their applications to a range of market niches are more likely to flourish in today's economy [7]. The support services provided by package vendors include ongoing stream of releases and upgrades to fix bugs and the vendors are the vendor is responsible for correcting bugs in the source code [3]. Vendors provide upgrades to accommodate technical developments [3].

Summarizing the above cited literature, we introduce the reason why vendors in their perspective provide upgrades and are illustrated in Figure 1. Among the criteria above, fixing Customer Identified Issues is often considered by vendors release after release, as it is one of the major factors when driving customer satisfaction. When issues in the system came crossed by a customer, it's necessary to address them as soon as the current release. For example, if the performance of the software is not a major concern in the current software release, this criterion would receive less time and man-power allocation. On the other hand, if the major objective for the SCM vendor is market expansion, criterion such as software integration and functionality expansion would be considered with higher priorities, and thus will be invested with more time and manpower. Furthermore, module and functionality enhancement serves both purposes of customer satisfaction improvement as well as market expansion. Therefore, they would also be considered during the software release decision process.

With different business objectives, priorities and target customers, the scope and the technology platform of the SCM solution provided by different vendors varies. Business managers need to study 
the solutions available carefully with thorough consideration of its own business requirements when choosing the SCM solution for SCM integration or making the upgrading decision.

\section{Customer perspective}

Business managers evaluate SCM solutions when making integration or upgrading decision from different perspectives than the SCM solution providers. Vendors traditionally provide two major types of maintenance and upgrades: (1) support packages or legal change patches to the installed version, and (2) new version of the system for upgrades. In particular, organizations typically upgrade to a new system in order to realize the benefits of substantial new functionality [20]. Ng [20] has analyzed maintenance data collected from an organization in the process of upgrading its ERP and SAP R/3 system to examine a decision framework for aiding an ERP user-organization in deciding if and when it should upgrade their ERP to a new version and has addressed the following questions from the ERP user-organization perspective: (1) the fundamental factors driving ERP maintenance and decision, (2) the difference of these factors from those for in-house software, and (3) the performance of existing software and hardware replacement models when making the ERP maintenance and upgrade decisions. Ng [20] observed that the factors surrounding ERP maintenance and upgrade are found to be different from those in-house software maintenance in three areas: (1) to realize increased benefits from the system, (2) to incorporate new functionality, and (3) to associate with less legal change patch maintenance distributed by the ERP vendors, thereby reducing the efforts associated with incorporating these patches and has concluded that exiting in-house software and hardware replacement models are not sufficient for an ERP model.

To better understand SCM integration/upgrading issues and on the basis of our discussions with business managers and SCM IT professionals, we have identified eight major elements, shown in Figure 2, affecting integration/upgrade decisions. Figure 2 illustrates the customer perspectives of a new release of the software, i.e., how customers perceive the new release of software. Each element represents an issue facing the business when making the decision. For any particular problem or issue, managers may apply analysis or decision support tools. In this section, we provide a brief description of the basic content for each of these elements.

To help order our discussion, we have divided the key SCM integration/upgrading decision factors of the customers into eight elements. We identified these eight elements from our discussions with business managers, as well as SCM IT professionals. Each element represents an issue facing the business when making the decision. For any particular problem or issue, managers may apply analysis or decision support tools. For each of the eight elements, a brief description of the basic content is provided.

Software Quality pertains to both functional and

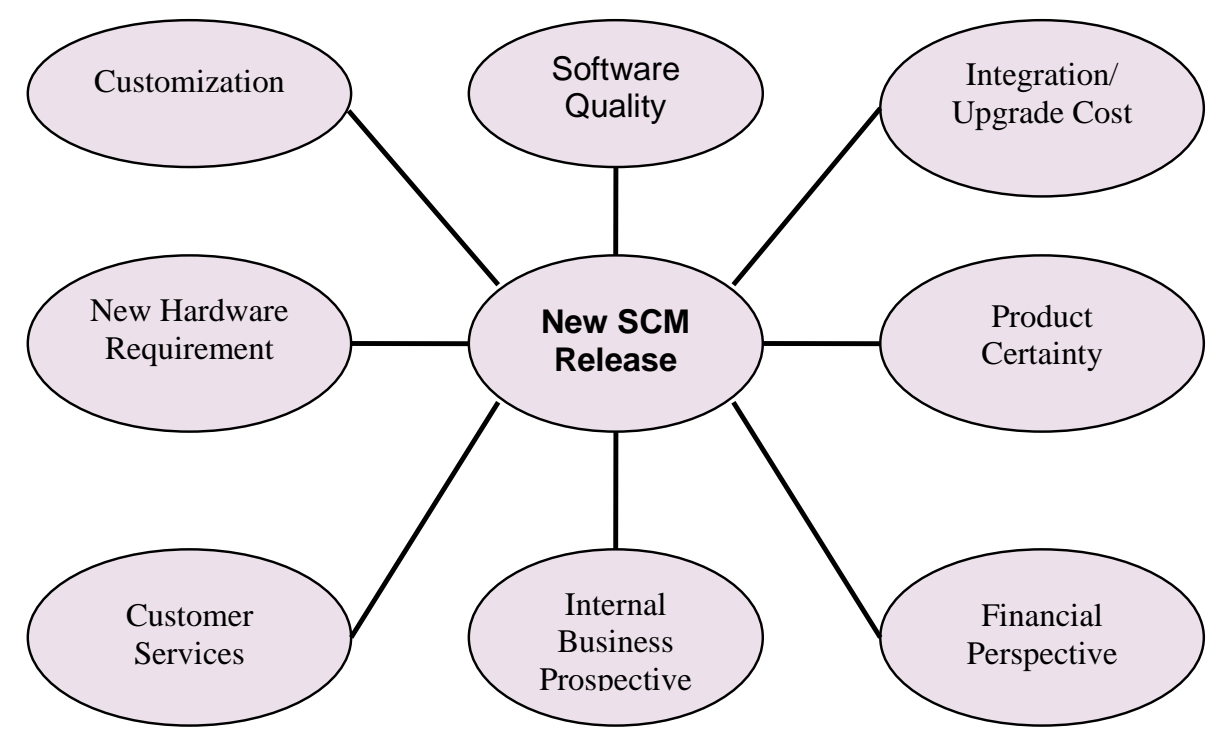

Figure 2: Key Elements in SCM Integration/Upgrading Decision Making 
technical aspects on the solution. The solution not only needs to perform the way supposed to help increase the supply chain efficiency, but also needs to be able to support the desirable number of concurrent users. In addition, acceptable performance of the software is also identified as the quality of software.

As in most business decisions, the Cost of SCM Integration/Upgrading should be considered as one of the most important factors. Cost of the solution package and cost of the services provided by SCM vendors fall into this category, as does the cost for in-house resources or materials needed for the integration or upgrading, etc. The upgrade cost, similar to the initial implementation, consists of software cost, hardware cost, user training, consultancy fees, and the upgrade implementation. A new version which has more functionality, flexibility, and extensibility will generally cost more to upgrade According to some estimates, some software for instance, SAP R/3 upgrade cost users 25-30 percent of initial investment [27].

Software Certainty encompasses all the defined "facts" of the SCM solution - the current functionalities supported, the number of concurrent users supported, to name a few. In particular, standardization of the system play a major role in their data communication facilities and personnel training but also improve their business processes and facilitate collaboration between partners. This can be supported by the use of an integrated ERP. According to Vice President of Supply Chain at NIBCO, "Having a standardized system across our network of plants helps us do many more things remotely than before. Further, it reduces personnel training expenses and helps us leverage expertise across our plants. Personnel can move from one factory to another and be ramped up very quicklythis makes our associates even more agile and flexible" [5]. In addition, the software performance defined by vendors also belongs to this category, such as time needed to process 100,000 packages through the warehouse.

Financial Perspective examines the Return on Investments (ROI) on the integration/upgrading decision. The type and period of returns are included in this aspect. In addition, the cost reduction is considered as one of the financial perspectives during the decision making process.

Internal Business Perspectives deals with business philosophy and issues, such as the time required for the integration/upgrading, potential business risks, etc. If a SCM solution comparatively takes too long to integrate or upgrade for a firm, it could pose great business risks and might simply not be a good fit. The Vice President of Supply Chain at
NIBCO stated that "we took the SAP implementation as an opportunity to redefine our supply chain business processes. The implementation was trigger to make it happen. It also helped us define and communicate our supply chain philosophy" [5].

Customer Services is to be considered the most important factors by many business managers and SCM professionals. It examines not only the service provided during the integration or upgrading, but also the ones provided by vendors post-installation. This can be not only tried out through business's own experience, but also examined through industry reputations, vendor company culture, etc. Sahin and Zahedi [25] have carefully examined the maintenance issues faced by the vendors. In their view, a software vendor has to decide if and when these patches or upgrades should be introduced to the user-organizations. Since these patches and upgrades could be costly to the vendor and at the same time delaying them could degrade customer satisfaction and affect the revenues. They propose that a software vendor may make software/upgrade decisions in response to the current level of customer satisfaction, which directly determines the revenues of the vendor. For instance, according to Brown et al. (2003), before the go-live in NIBCO, management developed a new metric to better capture and monitors its ability to satisfy its customers. "Internally called Big 6, NIBCO developed a perfect order metric to capture the percentage of orders that were perfectly fulfilled. The metric is calculated by multiplying six elements, which include order accuracy, product availability, and order-to-ship timeliness.” According to the Director of Supply Chain System at NIBCO, "you do not compete in our market any more with product and price; you've got to compete with service ...the Big 6 metric became a large part of our culture” [5].

New Hardware Requirement is listed a separate elements because not all integration or upgrading requires this additional investments. This area deals with all necessary or recommended new hardware for the integration or upgrading, such as servers, RFID devices, terminals/PCs, etc. Some midsize to smaller firms who would like to minimize their total investment in project might take this element into great considerations. For example CIO at NIBCO argued that they made a strategic decision to stay relatively current on both hardware and software. They upgraded SAP every 18 to 24 months [5].

Finally, customization presents the configuration flexibility provided by the solution. As indicated by Granter research report, customization ability has become one of the latest business drivers in the SCM market. This elements addresses the 
customization as simple as changing the security setting for members of the firm, to as complicate as total business process re-engineering by redesign the entire business work flow. For instance, NIBCO re-engineered its supply chain process with the initial implementation of SAP R/3, and replaced the long-established forecast-push approach with a demand-pull approach in supplying product to customers (Brown et al 2003). This initiative significantly affected all aspects of NIBCO's supply chain, cutting across customer service, the distribution system, manufacturing operations, and procurement. This new system is notable due to: (1) customization and its reliance on actual customer orders vs. demand forecast as the driver for day-today replenishment, and (2) the direction of triggers for the movement of product from the marketplace rather than from the manufacturer.

\section{SCM INTEGRATION/UPGRADING FRAMEWORK}

With the factors considered by SCM solution providers as well as key elements considered by customers during the SCM integration/upgrading decision making process, the following framework, shown in Figure 3, can be developed to guide the decision process for both customers and vendors. The framework poses that these general measurements lead to general perpetual measures of net benefits of integration and upgrades. These general perpetual measures of net benefits of integration and upgrades lead to the organizations' net benefits as established by Seddon's as well as DeLone and McLean's models [8, 26]. We use the customarily maintenance classifications that include adaptive, corrective, perfective, and preventive [16, 24, 28] as the basis for our framework. Adaptive, preventive, and perfective interventions are regarded as new software versions, while corrective maintenance is modeled by a random process under the hypothesis assumed for reliability modeling [17]. These maintenance factors that get enabled in the integration features and upgrades by the vendors result in customer satisfaction and finally as performance benefits to both organizations. The new framework is illustrated in Figure 3 and the various factors of this framework are discussed in this section.

\section{Adaptive maintenance}

From the SCM solution provider perspective, this indicates the changes in the software environment requirements, such as new functional and technical requirements, they need to consider when planning for the new software release. As the SCM software market become more and more mature and industry specific, include all necessary functionalities for the specific industry becomes more important than ever to stay in the competitive market. In addition, the SCM vendors need to continue adapting new/ advanced technology to upscale its software capacity in order to meet its customers' growth and compete in bigger part of the market. On the other hand, from the business managers' perspective, this indicates that managers need to evaluate the potential solution for integration or upgrading from both functional and technical aspects. Whether the functionalities provided can meet the business requirements and whether the technologies used can support current business processes and its potential growth down the road are questions to ask during the evaluation. In addition, the

customization ability of the solution should also be evaluated to ensure software flexibility to meet possible future changes in business.

\section{Perfective maintenance}

Perfective represents new requirements raised by customers or market. SCM vendors need to evaluate and prioritize the new requirements, and include them into the new software release to ensure customer satisfaction and stay competitive in the market. In addition, better software scalability is also necessary to meet business growth and new requirements. Furthermore, it is extremely important for SCM vender to provide what they say they will. "Do what we say we will do" not only gives a clear vision on what will be offered in the system, but also produces happier customers. As from the business managers'

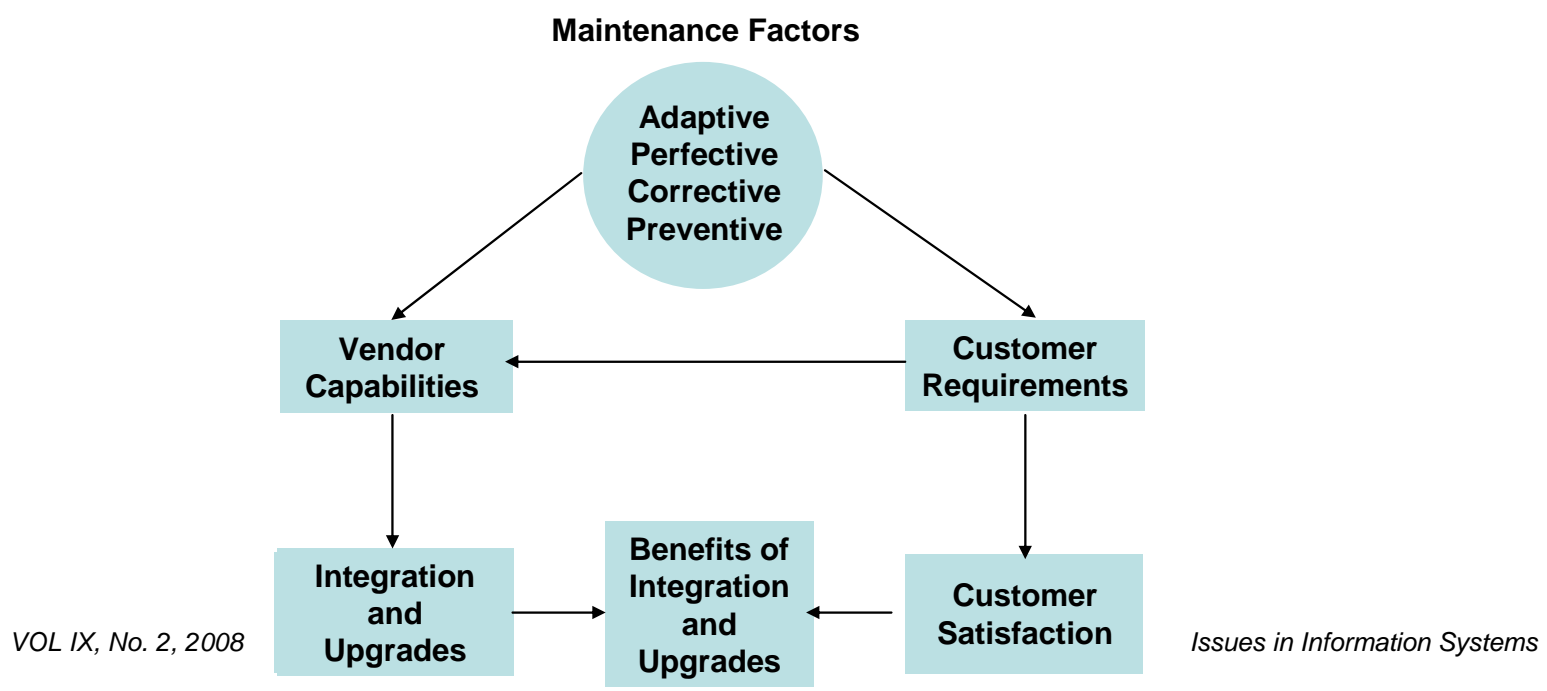

Figure 3. SCM Integration Upgrading Framework 
perspective, Perfective means good evaluation in areas such as customer service, software quality as well as new market trends during the decision process. SCM integration/upgrading are big projects with decent amount of investment in manpower, material and financial resources. Managers need to be certain that they are dealing with a company and a group of people they enjoy dealing with for a period of time of more than few months. Also, whether the SCM provider has clear vision on market trends should also be considered, although the technology/business process might not have been adapted by the firm yet. For example, a warehouse company might not be using the RFID technology currently, but it's necessary to obtain a solution with RFID enabled, or at least going to be. When the business is ready for the new technology, you can be certain that SCM solution is ready.

\section{Corrective maintenance}

Corrective is the part for SCM vendors to fix any problems found in current release of its solutions. These issues are not only limited to the ones identified by customers, but also include the ones discovered by the vendors themselves. By doing so along with comprehensive testing, the quality of the software can be ensured release after release and therefore achieve good customer satisfaction. For business managers', software and customer service quality is again evaluated with this strategy. This, once again, emphasized the importance of these two factors while making the integration/upgrading decision.

\section{Preventive maintenance}

Preventive is the strategy for preventing future problems. It includes good testing phase for the certainty of software quality, necessary new functionalities for new business requirements, as well as improved stability and scalability for business advancements. Being able to grow with the customers and always meet their needs will always lead to satisfied customers. Again, business managers will need to value the software certainty factor along with its unique business prospective to determine whether the solution is applicable at their firms.

As laid out in the framework in Figure 3, efficient integration and upgrading translates into great software product with good quality, comprehensive functionalities, flexibility, as well as excellent customer services. These factors all contribute to customer satisfaction. If SCM vendors follow the above framework to set their goals right, with a great effort, they sure will have satisfied customers with them every step of the way. In contrast, business managers should also uses the strategies presented above to select the most fitting solution that will drive their business to supply chain excellence.

\section{CONCLUSION AND FUTURE RESEARCH}

Traditionally, SCM implementations are built upon a linear, standard, and relatively stable view of the supply chain [13]. The supply chain is a linear modularized arrangement of actors from downstream to upstream of the chain interacting with each other in pairs. SCM solutions in this approach are product suites including several independent tools, each designed to optimize a single link in a predefined sequence [13]. We have covered eight key elements often being considered by business managers when making the supply chain management integration or upgrading decision. These elements appear to be the ones evaluated in practice and we believe once the right SCM integration/upgrading decision is made by evaluation of the these factors, opportunities should prove to be immeasurable. In the near future, we will conduct a survey to analyze the integration level of business applications. We will further expand the survey to test this framework.

\section{REFERENCES}

1. Alvarenga, C.A., and Schoenthaler, R.C. (2003). A New Take on Supply Chain Event Management, Supply Chain Management Review, May 01, 2003.

2. Baldassarre, M.T., Boffoli, N., Caivano, D., and Visaggio, G. (2005), Improving Dynamic Calibration through Statistical Process Control, 21st IEEE International Conference on Software Maintenance, Budapest, Hungary, September 26-29, pp. 273-282.

3. Brehm, L., Heinzl, A., and Markus, M.L. (2001). Tailoring ERP systems: A spectrum of choices and their implications. Proceedings of the 34th Hawaii International Conference on System Sciences, Maui, Hawaii, Vol.8, pp. 80178025.

4. Brehm, L., and Markus, M.L. (2000). The Divided Software Life Cycle of ERP Packages, Proceedings of 1st Global Information Technology Management (GITM) World Conference, Memphis (Tennessee, USA), 2000, pp. 43-46.

5. Brown, C., M. Tatikonda, and I. Vessey (2003), "NIBCO: My SAP Supply Chain Management”, Kelly School of Business, Indiana University. (Available at http://www11.sap.com/americas/solutions/ businesssuite/scm/pdf/nibco_full_report.pdf ; accessed on February 5, 2006). 
6. Chang, Y., and Makatsoris, H. (2001). Supply chain modeling using simulation. International Journal of Simulation, Vol. 2, No. 1, 24-30.

7. David, J.S., McCarthy, W.E., and Sommer, B.S. (2003). Agility: The key to survival of the fittest in the software market. Communications of the ACM, Vol. 46, No. 5, pp. $65-69$.

8. DeLone, W.J., and McLean, E.R. (1992). Information systems success: The quest for the dependent variable. Information Systems Research, Vol. 3, No. 1, pp. 6095.

9. Ferguson, J.R., and DeRiso, M.E. (1994). Software Acquisition: A Comparison of DoD and Commercial Practices, Software Engineering Institute, Special Report CMU/SEI-94-SR-9, October 1994.

10. Fox, M.S., Barbuceanu, M., and Teigen, R. (2000). Agent-Oriented Supply-Chain Management. The International Journal of Flexible Manufacturing Systems, Vol.12, pp 165-188.

11. Frohlich, M.T., and Westbrook, R. (2001). Arcs of integration: An international study of supply chain strategies. Journal of Operations Management, Vol. 19, pp 185200.

12. Hicks, M., and Nettles, S. (2005). Dynamic software updating, ACM Transactions on Programming Languages and Systems, Vol. 27, No. 6, pp 1049 1096.

13. Kov, G.L., Paganelli, P. 2003. A planning and management infrastructure for large, complex, distributed projects-beyond ERP and SCM. Computers in Industry 51, 165-183.

14. Kumar, K. (2001). Technology for supporting supply chain management: Introduction. Communications of the ACM, Vol. 44, No. 6, pp. 58 - 61.

15. Lejeune, M.A., and Yakova, N. 2005. On characterizing the 4 C's in supply chain management. Journal of Operations Management 23 (5), 81-100.

16. Lientz, B., Swanson, E.B. Problems in application software maintenance. Communications of the ACM, 24 (11), 1981, 763-769.

17. Lyu, M.R. Handbook of Software Reliability Engineering, IEEE Computer Society Press, Los Alamitos, CA, 1995.

18. Lucas, H. (1971). Performance Evaluation and Monitoring. ACM Computing Surveys, Vol. 3, No. 3, pp $79-91$.

19. Morgan, T.P. 2006. Supply Chain Software Sales Still Growing, According to AMR. IT Jungle, Volume 15, Number 37 -- September 18, 2006.

20. Ng, C.S.P. (2001). A decision framework for enterprise resource planning maintenance and upgrade: A client perspective. Journal of Software Maintenance and Evolution: Research and Practice, Vol. 13, No. 6, pp 431-468.

21. Ng, C.S.P., Chan, T., and Gable, G.G. (2001). A client-benefits oriented taxonomy of ERP maintenance. Proceedings of International Conference on Software Maintenance, IEEE Computer Society, Los Alamitos, CA, pp 528-537.

22. Niessink, F., and van Vliet, H. (2000). Software maintenance from a service perspective. Journal of Software Maintenance: Research and Practice, Vol. 12, No. 2, pp. 103-120.

23. Porter, M. (1985), Competitive Advantage, The Free Press, New York, NY.

24. Pressman, Roger. Software Enqineerinq: A Practitioner's Clpproach. New York : McGraw Hill, 1982.

25. Sahin, I, and F. Zahedi (2001), “Control Limit Policies for Warranty, Maintenance and Upgrade of Software Systems" IIE Transactions, September, Issue: 33(9): $729-745$.

26. Seddon, P.B. (1997). A respecification and extension of the DeLone and McLean Model of IS Success. Information Systems Research, Vol. 8, No. 3, pp. 240-253.

27. Songini, M.L. (2000), "Users vent Frustration over Oracle CRM/ERP Upgrades, "Computerworld; 34(44):105.

28. Swanson, E.B. The dimensions of maintenance. Proc. 2nd Int. Conf. on Software Engineering. San Francisco, October 13-15, 1976.

29. Valentine, L. (2004). Who's Winning the Supply-Chain War? BPM Today, March 30, 2004.

30. Yakimovich, D., Bieman, J.M., and Basili, V.R. (1999). Software architecture classification for estimating the cost of COTS integration, Proceedings of the 21st international conference on Software engineering, Los Angeles, California, pp. $296-302$.

31. Yen, D.C., Chou, D.C., and Chang, J. 2002. A synergic analysis for Web-based enterprise resources planning systems. Computer Standards \& Interfaces, 24, 337-346. 